\title{
Seismic Design of Steel Structures with Lead-Extrusion Dampers as Knee Braces
}

\author{
${ }^{1}$ Ali Naser, ${ }^{2}$ Habib Saeed Monir, ${ }^{2}$ Hassan Ahmadi, ${ }^{3}$ Sahar Mohammadzadeh, \\ ${ }^{1}$ Behzad Mohammadnasab nejad, ${ }^{4}$ Mehdi Eskandarzade \\ ${ }^{1}$ Sama technical and vocational training college, Islamic Azad University, sarab branch, sarab, iran \\ ${ }^{2}$ Department of Civil Engineering, Urmia University, Iran \\ ${ }^{3}$ Department of Civil Engineering, Sharif University of Technology, Tehran, Iran \\ ${ }^{4}$ Department of Mechanical Engineering, Urmia University of Technology, Iran
}

\begin{abstract}
In this paper Lead-Extrusion Dampers (LED) are considered as knee brace in steel frames. Considering that lead dampers as knee braces don't clog structural panels, so this characteristic can solve brace problems from architectural view. Knee brace has a good function in controlling seismic movements of multi-story structures. The results indicate that maximum displacements have been reduced up to between $20 \%$ and $60 \%$. Lead dampers act properly in absorbing the energy induced by earthquake where these dampers dissipate about $60 \%$ of total energy.
\end{abstract}

Keywords- Lead-extrusion damper, energy dissipation, knee brace

\section{Introduction}

The recent severe earthquakes have had huge economical and spiritual effects in the human society. Therefore, the necessity of seismic resistance of structures and buildings is obvious and must be considered in the design of structures. One of the most useful and economical methods in seismic resistance of building is using of structure protecting systems. Structure protecting systems can be divided into three categories [1]. First group is the active and semi-active systems, in which the movements of structures are controlled by complicated controlling systems which apply external energy to protect the structure from earthquake. The second groups are seismic isolating systems which are usually applied in the foundation of structures. The third group is the application of passive energy systems which lead dampers are included in this group [2,3]. Several analytical and experimental studies show that passive dampers can effectively reduce the seismic drifts. In this case, most of load bearing elements act in the linear zone and energy is dissipated in the absorbers [4]. Acceptance of non-linear deformations that design cods permit in structural deformations, results in considerable loss in the structural members. In recent years several mechanisms have been used for designing effective and economical dampers. These systems include hystersis metal dampers, frictional devices, viscous and visco-elastic dampers, tuned mass systems, adjusted liquid dampers and so on [5]. Metal dampers have been used more frequently than the other systems and there were considerable improvements, related to these dampers in recent years. Lead-extrusion damper (LED) is one of these dampers which have found great attentions recently. Lead extrusion dampers have been successfully used in most countries to prevent seismic effects. This technology was introduced First in New-Zealand. Then many instruments of these kinds were experimented in many countries. Many studies are dedicated to applications of several lead- extrusion dampers for using as energy dissipater [6].

(a)

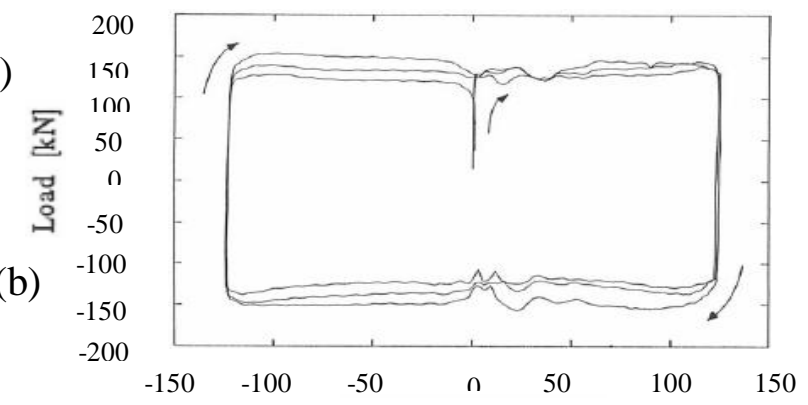

Fig 2. Hvsterisis curve of lead extrusion damper
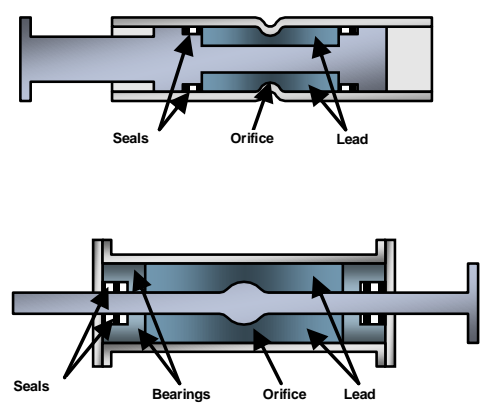

Fig 1. Two sample of lead extrusion dampers

Lead-extrusion dampers (LED), in which mechanical energy changes to heat during the process of lead injection into a tube, are suitable permanent devices for absorption of the cinematic energy of structure during earthquake. The configuration of this damper is simple but its design is not so. The behavior of these dampers is 
similar to frictional dampers, because their hystersis loops are rectangular and in the frequencies that are in the zone of earthquake frequencies are practically velocity independent [7]. Because of recovery process, recrystallization and particle growth that from during lead injection and afterwards [6] lead gains its initial shape after deformation, so lead-extrusion dampers (LED) have stable and permanent performance. Two kinds of Lead dampers are shown in (Fig. 1) and a typical hystersis loop for these devices is shown in (Fig. 2). Approximately rectangular figure shows that these dampers have tendency to maximize energy dissipation.

\section{Materials and Methods}

The LED absorbs vibration energy by plastic deformation of lead. When lead is extruded, the work is done as lead is forced through the orifice during the structural deformation. During an earthquake, LED limits the build up of destructive oscillations in a structure by absorbing energy [8]. Two cylindrical types of LED are shown in Fig. 1. They consist of a cylindrical tube, a bulged shaft and lead filling the space between them. As the shaft moves relative to the cylindrical tube, the lead extrudes through the orifice path formed by the bulge and the cylindrical tube. The successful performance of LED depends on the quality of lead which recovers and re-crystallizes rapidly. Lead-extrusion dampers can be modeled and designed both analytically and numerically. In this research, several tips of this damper have been modeled numerically in various kinds of the shape, size and restraint conditions. Fig. 3 shows two numerical model which have been used in this study for designing of lead dampers. The differences are due to restraint conditions and arch angles. Betzalel's formula [6] solves many problems and unknowns in the field of necessary parameters of Lead dampers. According to formula (1), we can calculate the force in these dampers in the effect of steel rod displacement, or vice-versa, the displacement produced in the application of an applied force:

$$
P=K(1+\mu \operatorname{Cot} \alpha) \operatorname{Ln}\left[A_{1} / A_{2}\right]+K \mu[L / d]^{2}
$$

All of the parameters have been shown in (Fig. 4), in which: $\mathrm{K}$ is the yield strength of lead, $\mu=0.15$ is friction factor on the bulge; $\mathrm{L}$ is the movement length of steel rod, $\alpha=12^{\circ}$ is the angle of bulge in degrees; $\mathrm{A}_{1}$ is original cross - sectional area of lead; $\mathrm{A}_{2}$ is the extruded area of lead.
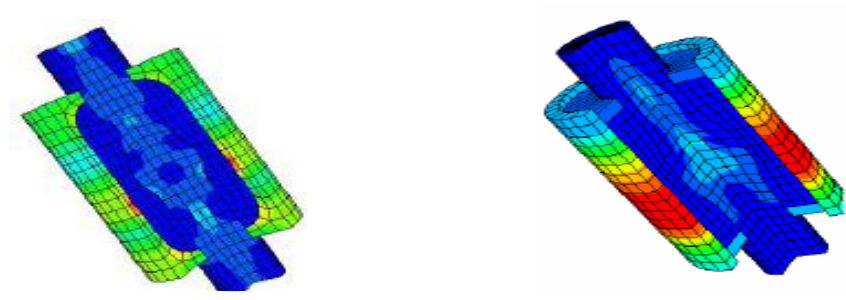

Fig 3. Two example of dampers model in finite element software

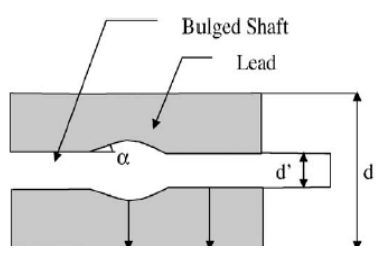

Fig 4. Lateral shear and determined

If $\mathrm{a}$ and $\mathrm{b}$ are inner and outer radius of cylinder in respect, for calculating tangential stress and radial stress at distance $r$ from its axis, formula (2), (3) can be used.

$$
\begin{gathered}
\sigma_{t}=\frac{a^{2} P_{i}}{b^{2}-a^{2}}\left\{1+\frac{b^{2}}{r^{2}}\right\} \\
\sigma_{r}=\frac{a^{2} P_{i}}{b^{2}-a^{2}}\left\{1-\frac{b^{2}}{r^{2}}\right\}
\end{gathered}
$$

In which $\sigma_{t}$ is tangential stress, $\sigma_{r}$ is radial stress. The results from these formulas are in good agreement with the results obtained by finite element software. The most important aim from this modeling and designing is the obtaining of important parameters (such as stiffness and yield force) for the proper performance of the damper. 
A sample displacement-force diagram which has been obtained by finite element software and indicates all of these parameters, is shown in Fig. 5 for instance. From this diagram and the formulas related to forcedisplacement, the stiffness and yielding force of the modeled damper can calculated to be used in the structure's model.

\section{Determination of Lead Sleev' S Length}

In order the energy to be dissipated properly by the LED during the vibration, there should be sufficient room for the steel rod to move inside the steel sleeve. For this purpose the minimum length of this sleeve can be calculated by simples' geometry relations among the structural components, referring to equations (4-6).

$$
\begin{gathered}
x_{1}=a \sqrt{2} \\
x_{2}=a \sqrt{2(1+\sin \alpha)} \\
\Delta x=a(\sqrt{2(1+\sin \alpha)}-\sqrt{2})
\end{gathered}
$$

In which $x_{1}$, is preliminary length of damper, $x_{2}$ is secondary length of damper, and $\Delta x$, is the length variation of damper (Fig. 6).

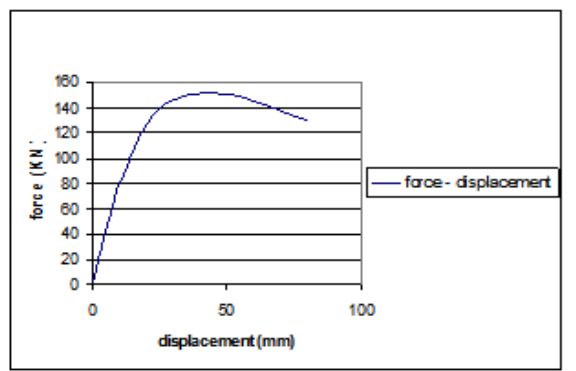

Fig 5. Example of force-displacement curve of damper

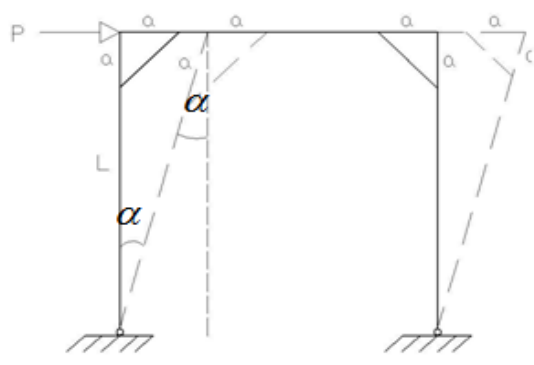

Fig 6. Geometry of deformed model

\section{Studied Structures}

There are many researches that offer utilizing of various types of dampers in structures [9]. In this study, the application of this damper in structures as a knee brace is investigated. Utilizing of knee braces at structures has many advantages, which the most important of them is that the panels are not blocked during application of such braces. After verification of the hystersis curve of lead- extrusion damper, it is used at the numerical model of the structure, in order to study the seismic behavior of steel structures of equipped by these dampers. The main objective of this research is the study of damper effect in energy absorption caused by earthquake as well as behavior of steel structures equipped with these dampers. In order to analysis the structural behavior, it needs to determine efficiency characteristics. Not only these characteristics need to be measurable but also they should determine the structural behavior under external and lateral loads. Displacement of floors, shear force of story, absorbed energy by the members and dampers are most important of such characteristics. To study damper behavior, 2 bending frame structures with 4 and 8 stories( Fig. 7) with same plan and spans (each story with $3.2 \mathrm{~m}$ height) were studied in such a way that the total height of 4 story structure was 12.8 and total height of 8 story structure was considered 25.6. For proper performances of dampers in structures equipped with dampers, in the spans which absorber have been used, lead extrusion damper as knee brace can be installed above and / or below the beams. The Fig. 8 shows the beam-column connections with knee braces placed both above and below the floor beams. The braces above the beams can be placed inside of curtain walls or partition walls, and those below the beams can be hidden above the ceiling. As the beam and column are connected by a hinge, the lateral load is mostly resisted by the braces. The beams and columns are generally stiffer than the lead extrusion damper as knee braces, and are expected to remain elastic even after the braces yield. In this paper we describe the lead extrusion damper as knee braces located only below the beam. The beam-column joints are considered to have hinge joint (Fig. 9). In locating these braces in the spans, it should be noticed that such braces are not alike to ordinary braces, in which longer spans performs than shorter one. In these dampers, the shorter span is better choice for damper application than the longer one. Besides, the yield limit of the dampers in the height of structures should be reduced for preventing from soft floor and better performance of system. 

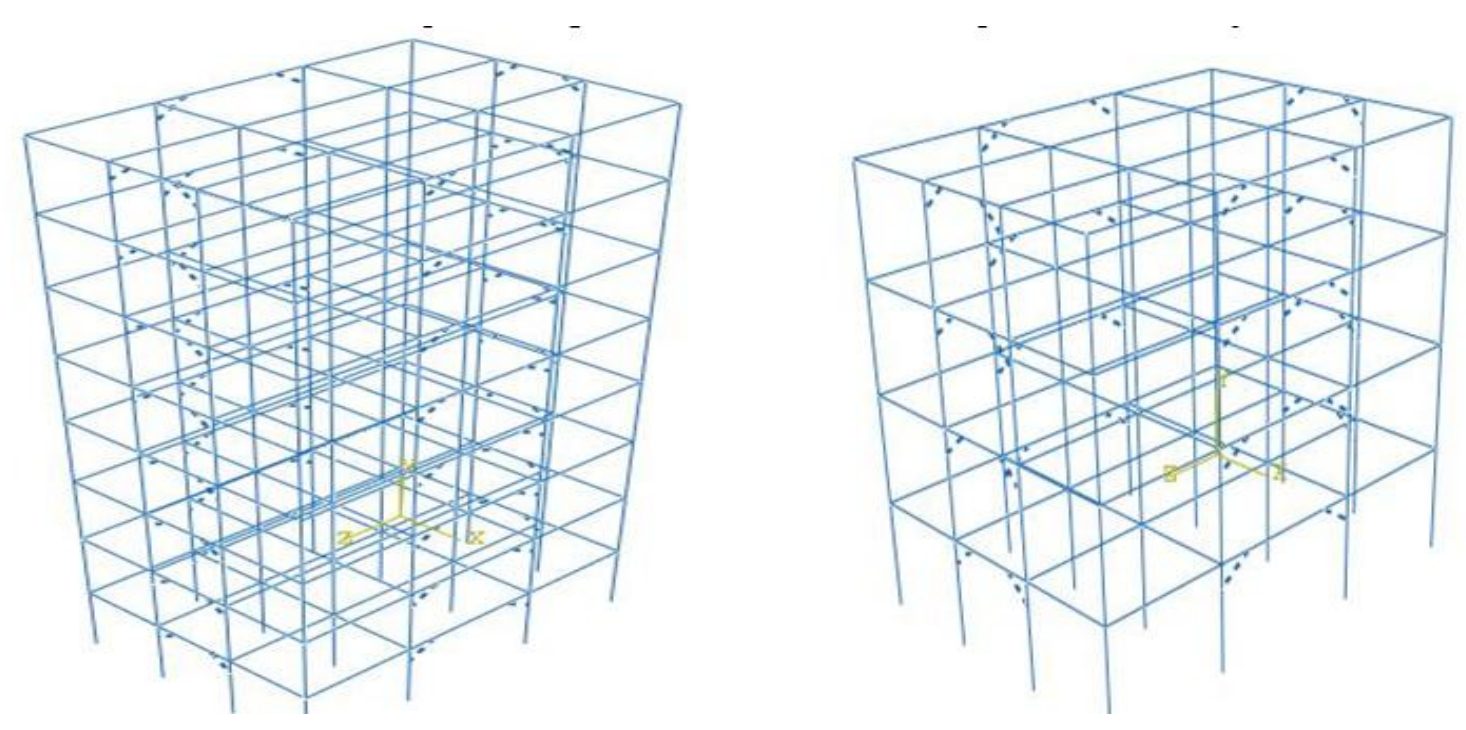

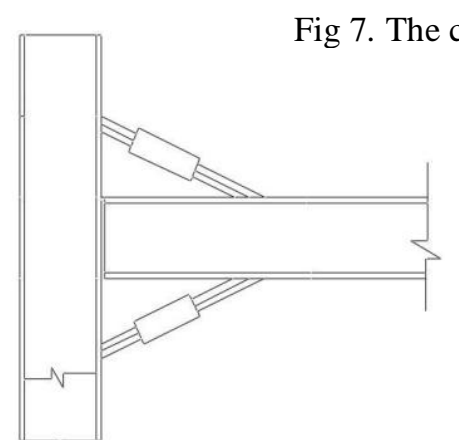

Fig 8. Side view of beam-column with LED

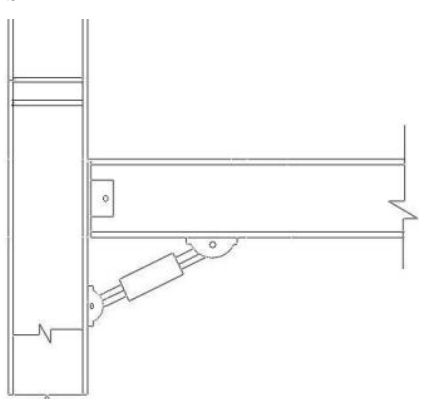

Fig 9. Models for ioints of LED to beam - column

According to a assumed design code necessity, the structure is considered to tolerate the excitations with the time-histories of Kobe \& E1 Centro earthquakes. Gravity loading and P- $\Delta$ effects are considered. Seismic acceleration in this analysis must be applied in the form of a function of time to the base of structure [10]. One of the advantages of time-history analysis, which can be used as linear and non-linear analysis, is that this approach can be used as standard dynamic analysis. The time-history analysis of structures equipped with LED indicates good behavior of these dampers in knee position. As shown in Figure 10, constant hysteretic loops, which is an ideal behavior for a damper, can be seen in all of them. In Fig. 10 for instance, the response of dampers in 4 story buildings are shown. Time-history of root lateral displacement with and without damper under Kobe earthquake is shown in Fig. 11. The period of the structure is also decreased, because of damper effect in increasing of the stiffness. The effect of knee braced in reducing roof lateral displacement is shown in this figure. It is obvious that many changes have been created in the structures with braces in comparison to structures without braces. Generally, the response of structures with dampers are decreased and in further studies it was seen that in taller buildings the response is more considerable in the case that the damper'ss yields limits are distributed linearly in the height. This is while these effects have without producing any architectural limitation or problem in the structures. Relative displacements and maximum story displacements in structures with and without dampers have been shown in Fig. 12 and 13. It is obvious that in structures with lead extrusion dampers, these parameters have been reduced by the factor of $20 \%$ and $60 \%$. 

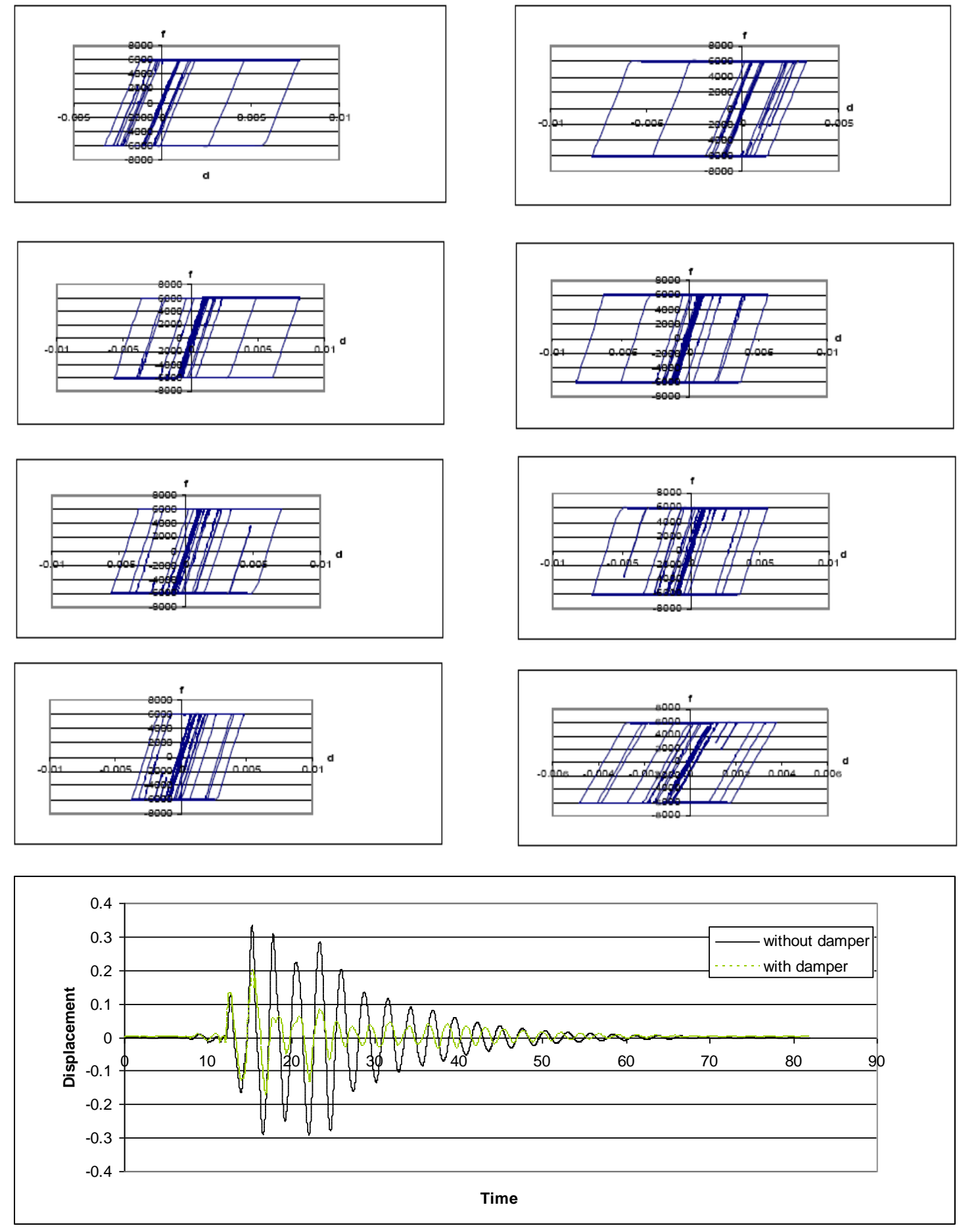

Fig 11. Time history of roof lateral displacement response
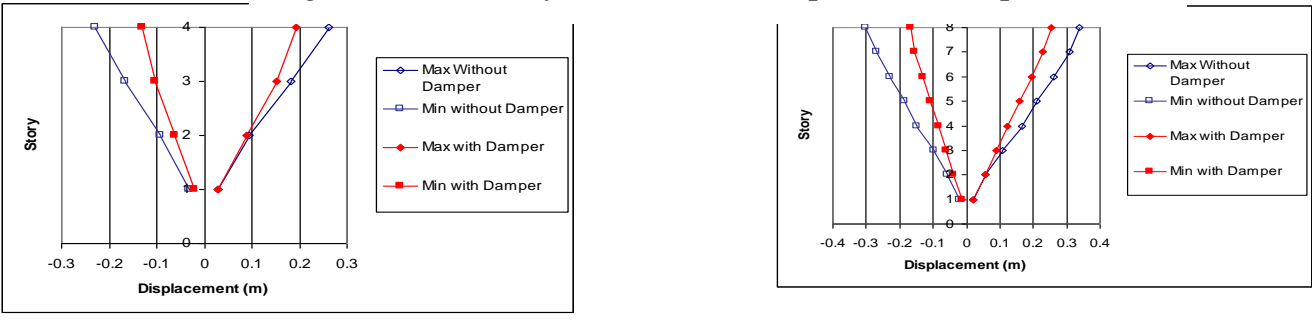

Fig 12. Maximum story displacement in 4 and 8 story structure 

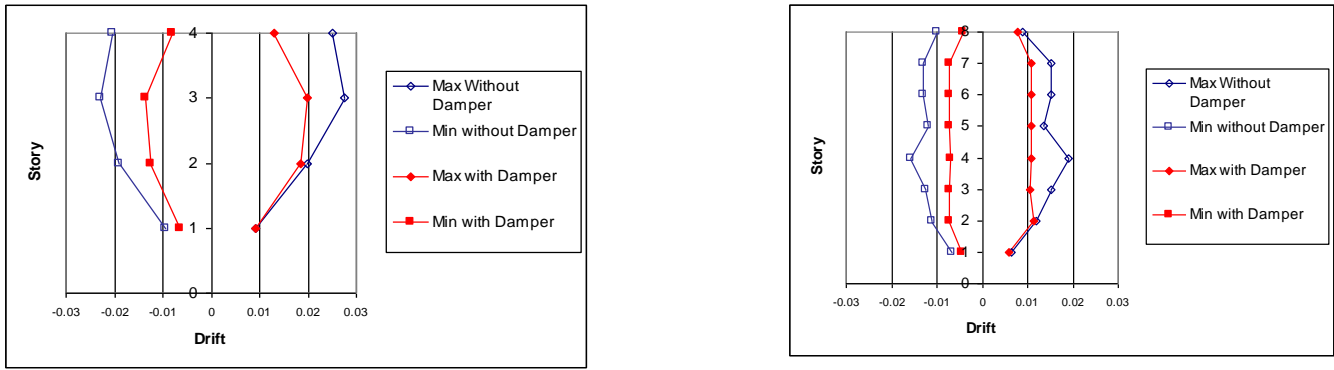

Fig 13. Maximum drift in 4 and 8 story structure

The important matter for LED as knee braces is their high energy absorbance. As shown in Fig. 14 these dampers dissipated about $60 \%$ of total energy under Kobe earthquake.

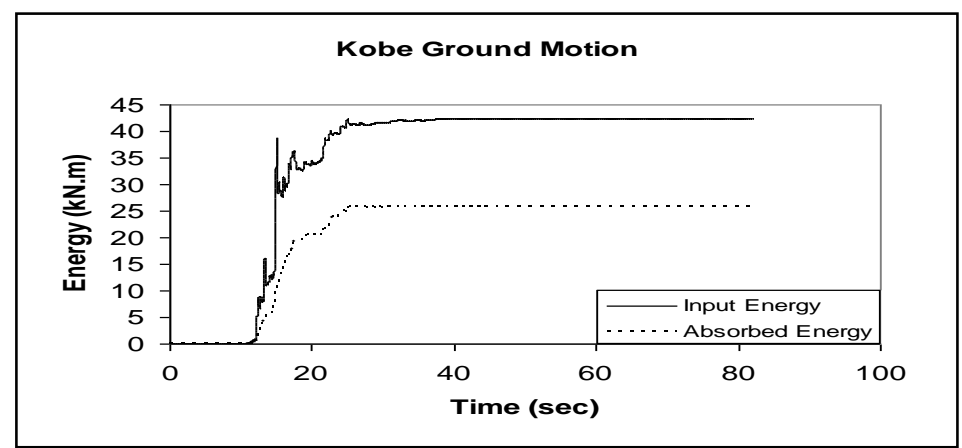

Fig 14. Time history of accumulated energy for Kobe

\section{Conclusion and Discussion}

As it was shown, LED has good capability in seismic controlling of multi-story buildings. It was discussed that the advantage of these systems is felt when these dampers have been used in knee braces. This solves many problems related to architectural aspects of the structure. As it was shown, using LED as knee-braces reduce story lateral drift between $20 \%$ and $60 \%$. By using of these systems, story displacements reduce considerably, and dampers absorb the most part of applied earthquake energy. And because of re-crystallizing and the reason that lead gains its original shape after deformation, these dampers have stable performance. By using of these systems, these dampers will work properly during the occurring of earthquake and afterwards, it means there is no need to replace them. Type of beam-column joints in the spans, which these devices have been applied, and also the span's length itself, are important parameters for a better performance of these dampers as knee braces.

\section{Acknowledgements}

The Authors would like to thank the managing director of Savalan Demir Yol Company for their supports.

\section{Reference}

[1] T.T. Soong, and G.F. Dargush, Passive Energy Dissipation Systems in Structural Engineering (Wiley Chichester, UK and NewYork, pp:80, 1997).

[2] L R Barroso, , J G Chase,and S J Hunt,. Resetable Smart-Dampers for Multi-Level Seismic hazard Mitigation of Steel Moment Frames. J. Structural. Control., 10(1) 2003, 41-58.

[3] G.W. Housner, , L.A. Bergman, T.K. Caughey, A.G. Chassiakos, R.O. Claus, S. F. Masri, R. E. Skelton, T. T. Soong, B. F. Spencer, and J. T. P. Yao, Structural Control: Past, Present, and Future.J. Eng. Mech., 123(9) 1997, 897-971.

[4] R. W.K. Chan and F. Albermani, Buckling-Restrained-Lug Connection for Energy Dissipation. J Advances in Structural Engineering 16(1), 2013, 11-20.

[5] I.S. Hwang, , Y.N. Huang, S.l. Yi and S.Y. Ho, Design Formulations for Supplemental Viscous Dampers to Building Structures. J. Structural. Eng., 134(1) 2008, 22-31.

[6] Y.M. Parulekar, G.R. Reddy, K K Vaze and H S. Kushwaha, Lead extrusion dampers for reducing seismic response of coolant channel assembly. J. Nuclear Eng. and Design 227(2), 2004, 175-183.

[7] Y.H. Chien, Fluid Dynamics and Behavior of Nonlinear Viscous Fluid Dampers, J. Structural. Eng., 134(2) 2008, 56-63.

[8] A. Finley and J Robert. Comparison of Methods for Computing Equivalent Viscous Damping Ratios of Structures with Added Viscous Damping, J. Structural Eng., 134(1) 2008, 32-44.

[9] T. L. Karavasilis, R. Sause, and J. M. Ricles. Seismic design and evaluation of steel moment-resisting frames with compressed elastomer dampers. Earthquake Engineering \& Structural Dynamics 41(3), 2012, 411-429.

[10] A.K Chopra., Dynamics of structures, Theory and Application to Earthquake Engineering (Prentice-Hall, New Delhi, pp: 431. By Anil K. Chopra, 2000) 